\title{
نماذج من مجددي الأزهر في العصر الحديث: الإمام محمد الغزالي والإمام محمد أبو زهرة
}

REFORMERS OF AL-AZHAR IN THE MODERN ERA:

IMAM MUHAMMAD AL-GHAZĀLI AND IMAM MUHAMMAD ABŪ ZAHRAH

\section{Ali Ali Gobaili Saged , Abdulmajid Obaid Hasan}

Academy of Islamic Studies University of Malaya. 50603. Kuala Lumpur. Malaysia.

Email: *saged@um.edu.my

\begin{abstract}
Khulasah
Universiti al-Azhar merupakan institusi yang melahirkan sosok pembaharu dan pemikir yang berperanan mengembangkan ilmu dan pemikiran dari kepelbagaian budaya dan tradisi. Institusi ini dikembangkan oleh sekumpulan ulama pemikir dan ilmuwan yang mengharmonikan disiplin ilmu klasik dan moden sesuai dengan zaman dan dalam masa yang sama teguh mempertahankan prinsip ajaran Islam. Ramai tokoh-tokoh yang lahir dalam perkembangannya dan khususnya pada abad moden ini, antaranya ialah Muḥammad al-Ghazāli dan Muhammad Abū Zahrah. Mereka boleh disebut sebagai perintis pembaharuan institusi ini. Kemunculan kedua-dua ulama ini adalah ketika berlakunya kecelaruan akidah, pencerobohan manhaj, pencemaran politik sekular dan kekontangan intelek dalam kalangan umat Islam. Mereka berperanan menyelesaikan permasalahan tersebut dan menghadapi arus pemikiran yang menyesatkan. Muhammad Abū Zahrah diiktiraf sebagai pembaharu separuh pertama abad ini yang ditandai dengan sumbangan pemikiran serta kedalaman inteleknya dalam menangani isu-isu pemikiran moden. Manakala Muḥammad al-Ghazāli dikenali sebagai
\end{abstract}


'perpustakaan bergerak'. Bagi beliau, pembangunan keilmuan Islam dapat menghalang pencerobohan pemikiran Yahudi dan sekular. Antara sumbangan beliau ialah mengharmonikan pemikiran Islam dengan pendekatan moden dan ilmiah. Dengan lebih dua ratus karya yang diterbitkan adalah sukar untuk menafikan ketokohan mereka sebagai pembaharu pemikiran Islam semasa.

Kata kunci: Mujaddid al-Azhar; Muhammad alGhazālī; Muhammad Abū Zahrah; pembaharu; ilmu dan pemikiran.

Abstract
Al-Azhar University is an institution that produces
reformers and thinkers throughout the world. It also
plays a role in developing knowledge and thought
from diverse cultures and traditions. This institution
was developed by a group of thinkers and scholars
who harmonized the classical and modern disciplines
according to the times, and in the meantime, firmly
upholds the principles of Islam. Among the thinkers
that emerged from the development of this institution
in the modern century were Muhammad al-Ghazāli
and Muhammad Abu Zahrah. They are the pioneers
of al-Azhar institutional reform in this modern era.
These two scholars emerge during the occurrence of
deviationist beliefs, methodologies intrusion, secular
political pollution, and intellectual drought among
Muslims. They play a role in solving these problems
and face misleading modern thinking by providing
complete solutions. Muhammad Abü Zahrah was
recognized as the reformer for the first half of this
century, marked by his intellectual contributions in
dealing with issues of modern thinking. While
Muhammad al-Ghazāli is known as a 'moving
library'. His development of Islamic knowledges
prevented the intrusion of Jewish and secular
thought. Among his contributions is to harmonize
Islamic thinking with modern and scientific
approaches. With over two hundred published works


Ali Saged \& Abdulmajid, "Reformers of al-Azhar in the Modern Era," Afkār Vol. 19 Special Issue (2017): 221-248

it is difficult to deny their loyalty as the reformers of contemporary Islamic thought.

Keywords: Reformers of al-Azhar; Muhammad alGhazālī; Muḥammad Abū Zahrah; renewal; knowledge and thought.

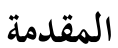

اتفقت كلمة الباحثين ان جامع وجامعة الأزهر تعتبر مصنع للتجديد الفكري، عن طريق ولادة مفكرين بحددين، وان العقلية الأزهرية تميزت بالمرونة، والقابلية، وبتسيد الفكر الإسلامي، والحضور الفاعل في عموم الزمان والمكان. وقبل الشروع في نماذج التجديد عن الإمامين نقدم بالتعريف بالتجديد:

\section{تعريف التجديد في اللغة والاصطلاح}

بحدد الشيء؛ يعني: صار جديدًا، وجدده؛ أي: صيَّهه جديدًا وكذلك أجدَّه واستجدّه. والجحديد هو نقيض الخلق، والجدة -بالكسر - هي مصدر الجديد وهي نقيض البلى، ويقال: "بلي بيت فلان ثم أجدّ بيتًا

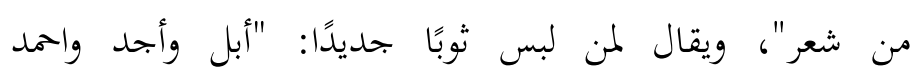
الكاسي." من ل1" وفي الاصطلاح: هو إحياء ما اندرس من العمل بالكتاب والسُنَّة والأمر بمقتضاهما.

${ }^{1}$ Muḥammad bin Mukarram Jamāl al-Dīn Ibn Manzūr al-Anșārī, Lisān al- 'Arab. (Beirut: Dār Șadir, 1414H), 111; Abū Nașr Ismā'ìl alJawharì al-Fārābì, al-Ṣiḥah, (Beirut: Dār al-`Ilm li al-Malāyin, 1987), 454.

${ }^{2}$ Ibn `Asākir, Tabi’ in Kazib al-Muftar (t.pt: tp., t.t.), 11. 
Ali Saged \& Abdulmajid, "Reformers of al-Azhar in the Modern Era," Afkār Vol. 19 Special Issue (2017): 221-248

وقد تواترت النصوص ان ديننا يتعرض للبلاء، والاندراس، وأن

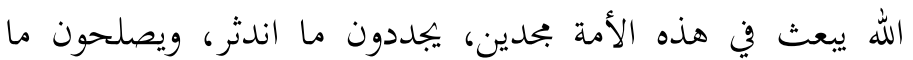

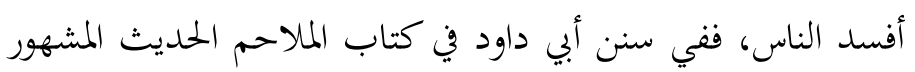

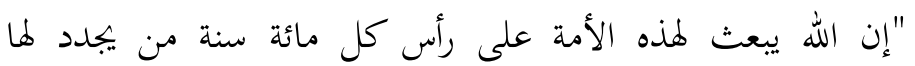
دينها". 3. ويمكن إجمال عناصر هذا التجديد على النحو التالي:

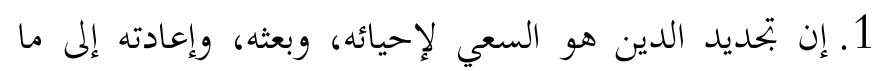
كان عليه في عهد السلف الأول. 2. ومن ضرورات التجديد حفظ نصوص الدين الأصلية صحيحة نقية حسب الضوابط والمعايير التي وضعت لذلك.

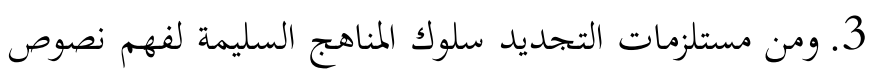
الدين وتلقي معانيها من الشروح التي قدمتها لها المدرسة الفكرية السُّنيّة.

4. وغاية التجديد جعل أحكام الدين نافذة مهيمنة على أوجه

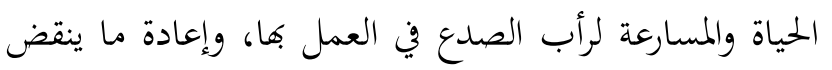
من عراها. 5. ومن توابع ذلك الاجتهاد، وهو وضع الحلول الإسلامية لكل طارئ، وتشريع الأحكام لكل حادث، وتوسيع دائرة أحكام

${ }^{3}$ Abū Dāwūd Sulaymān al-Sijistānì, Sunan Abū Dāwūd, Hadìth fīi Bāb ma Yudhkara fí Qarn li Mi'ah, no. 4291, ed. Muhammad Muhyī alDìn `Abd al-Hamid (Beirut: al-Maktabah al-'Așriyyah), 109. 
Ali Saged \& Abdulmajid, "Reformers of al-Azhar in the Modern Era," Afkār Vol. 19 Special Issue (2017): 221-248

الدين لتشمل ما كان نافعًا متفقًا مع التحاهات الدين ومقاصده وكلياته.

6. ومن خصائص التجديد تمييز ما هو من الدين وما يلتبس به،

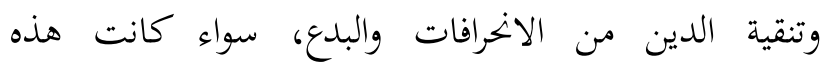
الانحرافات نابحة من عوامل داخلية في المجتمع المسلم أو كانت بتأثيرات خارجية.

وهذا بشكل عام ما يمكن اعتباره فكرة السلف عن معنى التجديد، وهو في بحمله سعي للتقريب بين واقع المجتمع المسلم في كل فئل

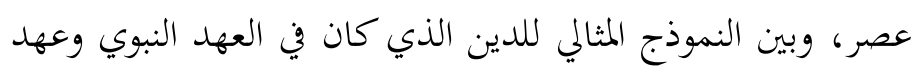
الصحابة.

مدرسة الأزهر معلم من معالم التجديد الإسلامي

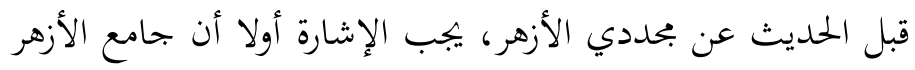

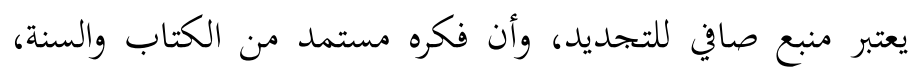

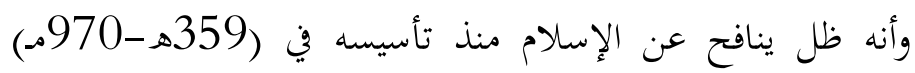
وحتى يومنا هذا، ونوره لازال يكشف الظلم، ويبدد الجهل، ويحيي الأمم. ومن أسس التجديد الأزهري : ولنال

${ }^{4}$ Maḥmūd Sa ìd Khayr Basțāmī, Mafhūm Tajdìd al-Dīn (Jeddah: Markaz al-Ta'ṣil li al-Dirasat wa al-Buhūth), 28. 
Ali Saged \& Abdulmajid, "Reformers of al-Azhar in the Modern Era," Afkār Vol. 19 Special Issue (2017): 221-248

1. العمق في التأليف واثراء المكتبة الإسلامية بكتب نوعية رائعة، فقل ان بتح فنا من الفنون، أو علما من العلوم الا ولعلماء الأزهر قصب السبق فيه.

2. تناول القضايا العصرية بتجرد، والوقوف أمام النوازل بدراسة تأصيلية، وعندما تمعن في المكتبة الإسلامية المعاصرة، تجد مؤلفات علماء الأزهر تنوعت، وضثملت علوم الاقتصاد والسياسية، والمقاصد. 3. التجديد في ولادة فكر ونوابغ ومفكرين. 4. العمق في مقاصد الشريعة، وملاحظة اسراره.

العمق في سبر اغوار الشريعة، وفهم الواقع، واستمرار المكنة التعليمية،

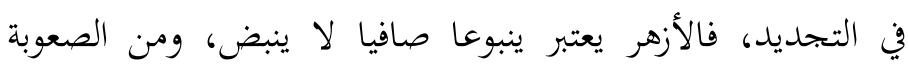

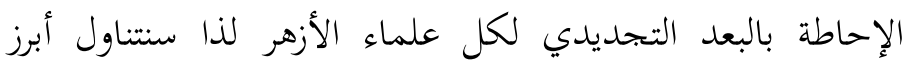

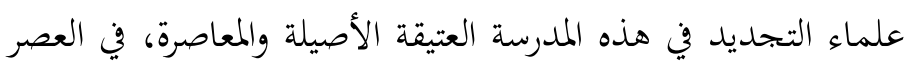
الحديث، وأبرز علماء الأزهر على النحو التالي.

معالم التجديد عن الإمام محمد الغزالي رحمه الله 5

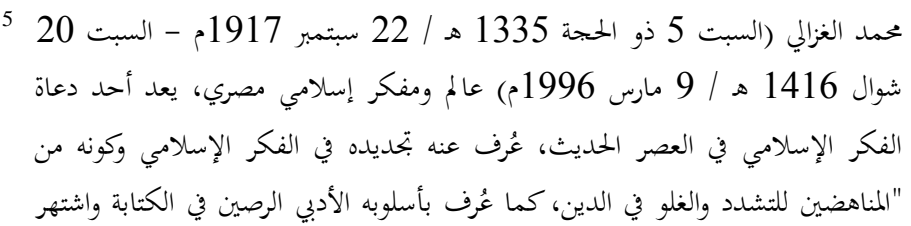


ينتمي الشيخ حمد الغزالي الي مدرسة التجديد الفكري المتطور, التي بدأت في القرن الماضي علي يد جمال الدين الأفغاني, ومحمد عبده, واستمرت من خلال الجهود الفكرية لرشيد رضا عبر بحلة المنار , ثم الجهود الإصلاحية لمصطفي المراغي في الأزهر الشريف, فأثمرت التكوين الفكري للشيخ محمد الغزالي (1917-1996م) الذي مثل الجيل الخامس في هذه المدرسة. 6 كتب المفكر الأزهري محمد عمارة مؤلفا رائع في فكر الإمام الغزالي، وهو يعتبر من أهم الكتب التي بينت عقلية الإمام ، أسمى الكتاب "الشيخ محمد الغزالي الموقع الفكري، والمعارك الفكري". 7 كما ألف الشيخ القرضاوي كتابا أسماه "الشيخ الغزالي كما عرفته،

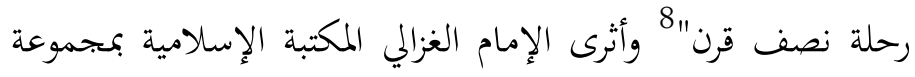
من المؤلفات اليانعة المثمرة، التي جعلت الباحثين يتسابقون في اقتناءها، ومطالعتها، ومن خلال ما ترك الإمام من ثروة علمية يمكننا وضع معالم التجديد في الآتي:

بلقب أديب الدعوة. سببت انتقادات الغزالي للأنظمة الحاكمة في العالم الإسلامي العديد

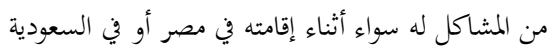

Data.bnf.fr, "Muhammad al-Gazālil", accessed 10 Oct 2015, http://data.bnf.fr/ark:/12148/cb12067665m

${ }^{6}$-Umar Sāmí, al-Ahrām, published 21 Oct 2013.

${ }^{7}$ Muhammad 'Imārah, al-Shaykh al-Ghazālì al-Wāqi`al-Fikr wa alMa`ārak al-Fikriyyah (Egypt: Dār al-Rashād li al-Nashr wa alTawzi`, 1997).

${ }^{8}$ Yūsuf al-Qarāḍāwì, al-Imām al-Ghazālì mā 'Araftah (Egypt: Dār alShurūq, 2008). 
Ali Saged \& Abdulmajid, "Reformers of al-Azhar in the Modern Era," Afkār Vol. 19 Special Issue (2017): 221-248

\section{التجديد في مفهوم الحياة والدين}

يضعنا الإمام الغزالي أمام منظومة متكاملة من الكتب ولمعياه والمنطلقات

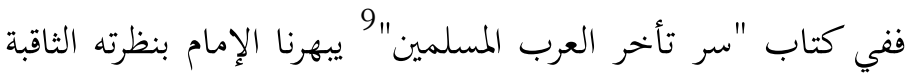
لمفهوم الحياة، والعلم، والسياسة، ففي مطلع الكتاب يقول:

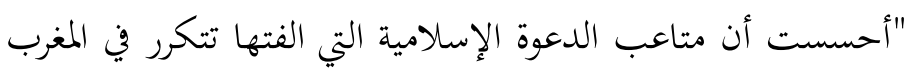

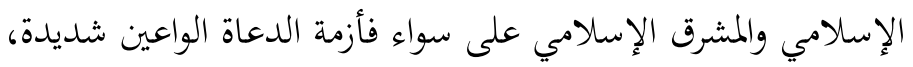
وأهل الذكر الجاعون بين القراءة والفقه قلة نادرة والاستعمار الثقافي لئي والاجتماعي والسياسي يعمل حثيثا.." فالإمام كان يعاني من تركة

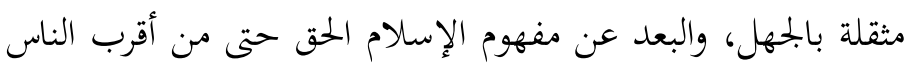
اليه الدعاة، وتأخر المسلمين من الناحية السياسية والاقتصادية والاجتماعية ومن خلال مطالعة فصول الكتاب يتبين الآتي:

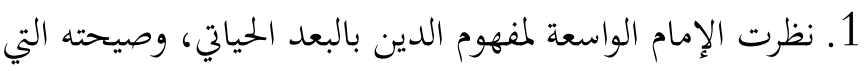
بلغت الآفاق عن واقع الأمة المتخلف، اقتصاديا وسياسيا، واجتماعيا.

2. معاناة الإمام من وجود أشباه الدعاة، من فهم قشور العلم، ولم يغوص في الأعماق.

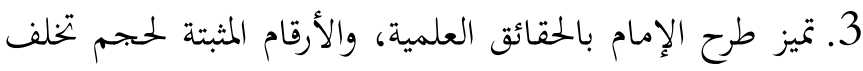
المسلمين، الذي أثر على حياقم، ودينهم.

${ }^{9}$ Muhammad al-Ghazālì, Sir Ta'akhkhar al- 'Arab al-Muslimīn (Egypt: Țab`ah Dār al-Nahḍah). 
Ali Saged \& Abdulmajid, "Reformers of al-Azhar in the Modern Era," Afkār Vol. 19 Special Issue (2017): 221-248

4. ومن أهم مؤلفات الإمام في تجديد مفهوم الحياة كتاب

$$
\text { "الإسلام والطاقات المعطلة" }
$$

كما ألف كتابه المشهور "جدد حياتك"11 وقد شرح الإمام

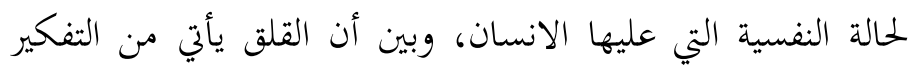

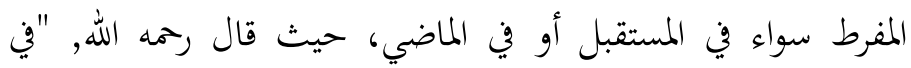

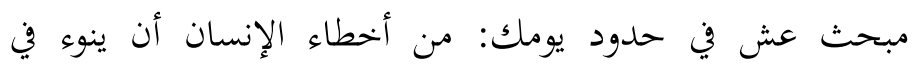

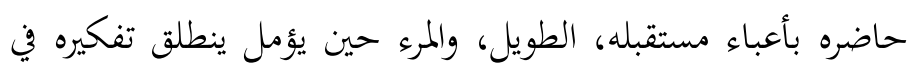

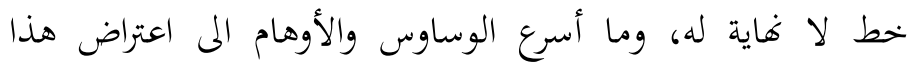

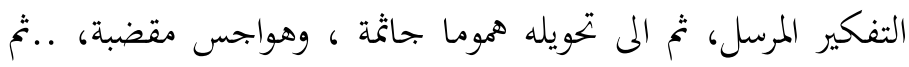

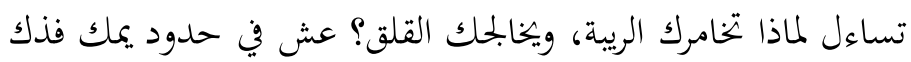

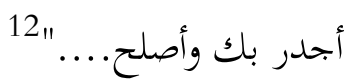

فاذ اختلف علينا الفهم وتشابهت أمامنا الطرق فلمرجع الفذ بلذ

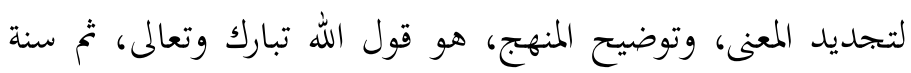
نبيه محمد صلى الله عليه وسلم. أن الاسلام كتبت لأحكامه الخلود

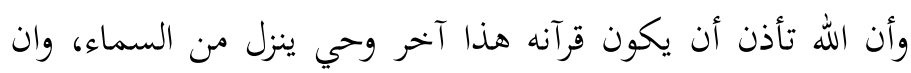
يكون محمد هذا مسك الخاتم في سلسلة الأنبياء.

${ }^{10}$ Muḥammad al-Ghazāli, al-Islām wa al-Ṭāqāt al-Mu'aț̣alah (Egypt: Dār al-Nahụah, 2005).

${ }^{11}$ Ibid.

${ }^{12}$ Muḥammad al-Ghazālī, Jaddid Hayāṭak (Egypt: Dār al-Da`wah li alNashr wa al-Tawzi', 1989). 23. 
Ali Saged \& Abdulmajid, "Reformers of al-Azhar in the Modern Era," Afkār Vol. 19 Special Issue (2017): 221-248

فلنعلم أن تجديد الدين لا يعني إرتكاب شئ من هذه المحاولات

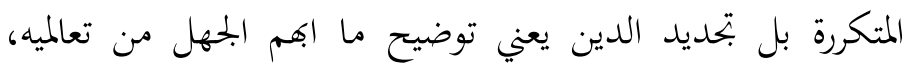

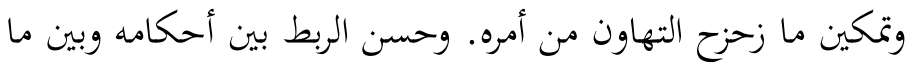

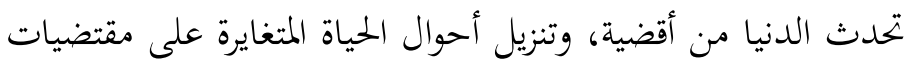

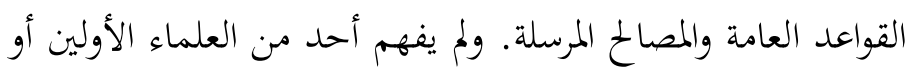

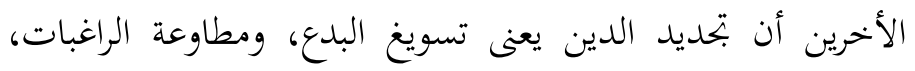

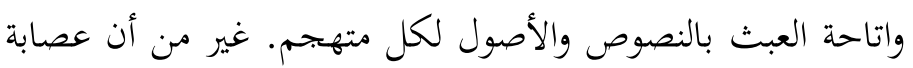

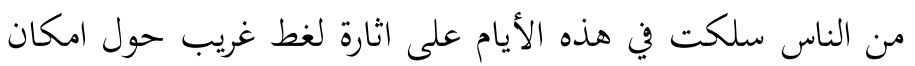
ما يسمونه "تطوير الدين" وجعل أحكامه ملائمة للعصر الحديث. 13

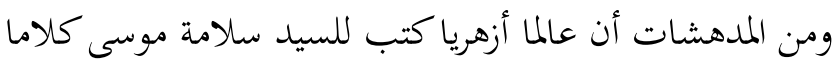
في هذا الموضوع جاء فيه: قلتم ختام التعقيب على كلمتي يوم الأحد

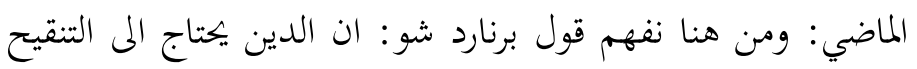

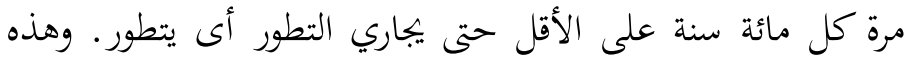

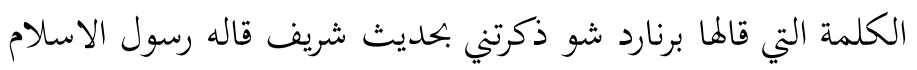

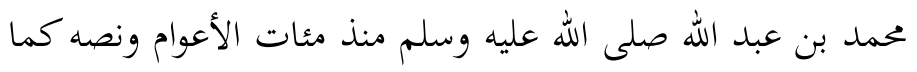

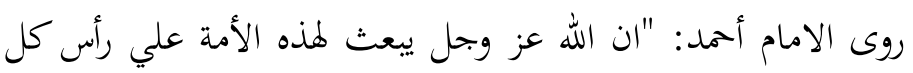

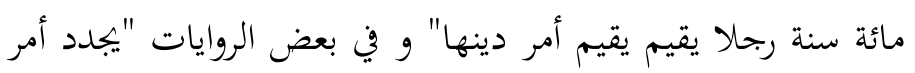

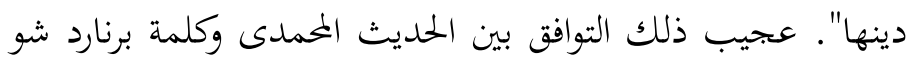
في تقدير المادة بمائة سنة، حيث تمس الحاجة الى التجديد والتنقيح

${ }^{13}$ Muhammad al-Ghazālì, Kayf Nafham al-Islām (Egypt: Dār alDa'wah, t.t) $157-158$. 
Ali Saged \& Abdulmajid, "Reformers of al-Azhar in the Modern Era," Afkār Vol. 19 Special Issue (2017): 221-248

بحاراة للتطور . وبهذه المناسبة أقول ان بعض الباحثين المعاصرين في

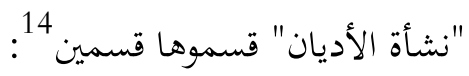

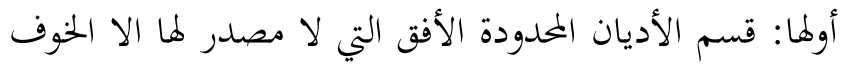

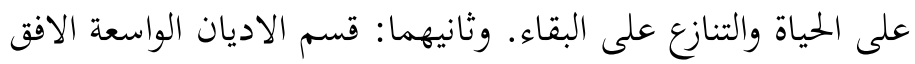

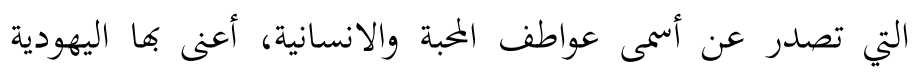
والنصرانية والإسلام.

ولو أن مشيخة الأزهر اليوم جرأوا على على اصدار مثل هذا القرار ضد

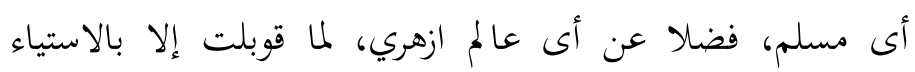

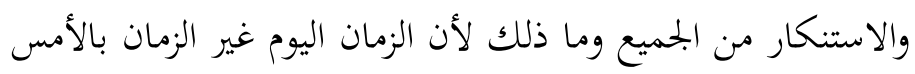
ولن ترجع عقارب الساعة الى الوراء، لأن التطور له حكمة القهار

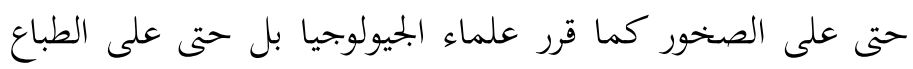

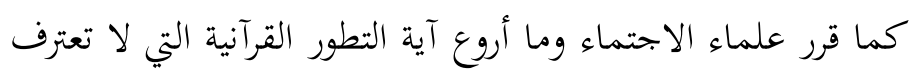

$$
\text { بالبقاء إلا للأصلح (الرعد: 17). } 15
$$

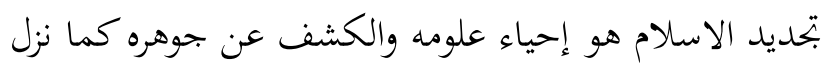

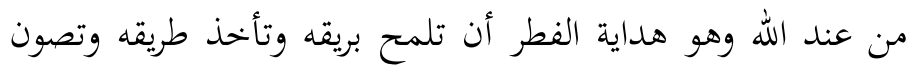
حقوقه بدافع من الحب والرضا والاقتناع و هو ايضا احكام الصلة بينه وبين قافلة الحياة لا ليلاحق سيرها فحسب بل بل ليشرف على على هذا

${ }^{14}$ Ibid., 159.

${ }^{15}$ Ibid., 160-161. 
Ali Saged \& Abdulmajid, "Reformers of al-Azhar in the Modern Era," Afkār Vol. 19 Special Issue (2017): 221-248

$$
\begin{aligned}
& \text { السير ويهيمن على ابتحاته وبذلك يكون الزمام لمدايات الرممن لا } \\
& \text { لهزات الشيطان. } 16
\end{aligned}
$$

\section{التجديد في مفهوم الدعوة والداعية:}

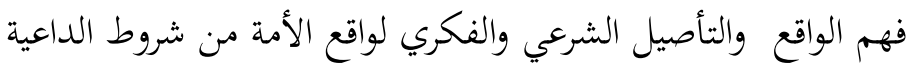

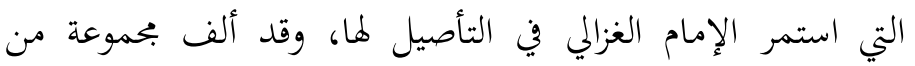
الكتب من أهمها (هموم داعية) يبدأ الكاتب هذا العمل العمل بمقولة مؤثرة تقول: 》الا أدرى لماذا يخالطني شعور بأنني أعيش فن القرن السابع أيام

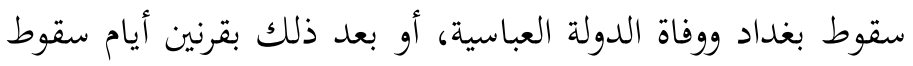
غرناطة واختفاء الإسلام من الأندلس؟!

هذذه الكلمات يعرض الكاتب لمموم الداعية الكبير خاصة في بحال الثقافة الإسلامية التي تحتاج إلى تنقية شاملة، وأن الدعاة في

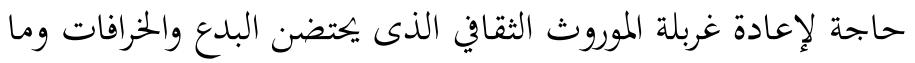
وفد به الاستعمار الثقافي للحضارة المنتصرة .. إنها محاولة لرصد أخطائنا لتنقية أفكارنا حتى تنمو الدعوة على أسس الإسلام الحنيف.

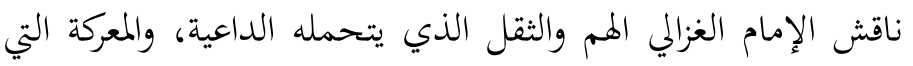
يجب ان يخوضها في زمن الفتن والابتلاءت.

درس الإمام حالة الداعية، وحالة المدعو، ووضع ملخصا

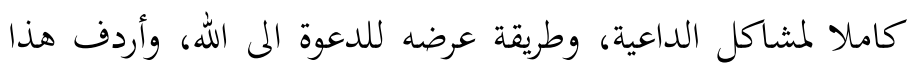

\footnotetext{
${ }^{16}$ Ibid., 164.
}

${ }^{17}$ Muḥammad al-Ghazālì, Hamūm Dā iyah (Egypt: Dār al-Nahḍah, 1996). 
Ali Saged \& Abdulmajid, "Reformers of al-Azhar in the Modern Era," Afkār Vol. 19 Special Issue (2017): 221-248

الكتاب بكتاب رائع يتعلق بالدعوة الاسلامية يبين فيها الإمام

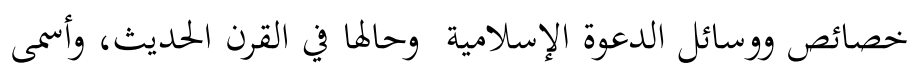

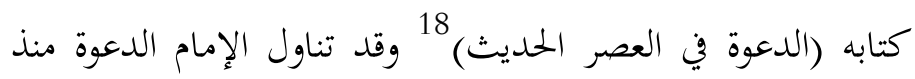

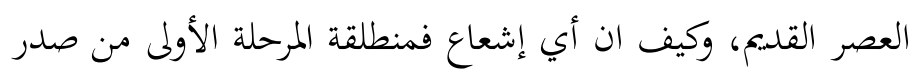

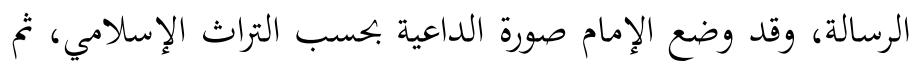

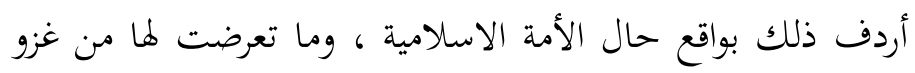

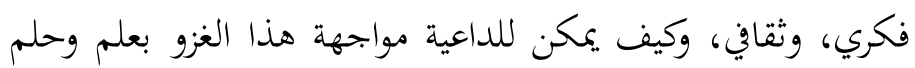
حجه وبرهان. ومن روائع الإمام الغزالي في ذلك الآني:

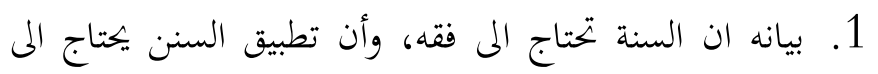
فقيهن حتى لا يسبب مشاكل وخلافا كما هو حاص حيث

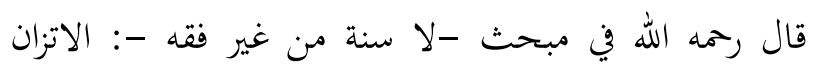
العقلي نصاب لابد من توفره في أي وجود ديني، إنه أساس التكليف الدينية، ثم هو يعد أساس التحدث الى الناس، باسم

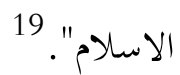
2. بيانه رحمه الله ان الدعوة فن وأسلوب حيث قال رحمه الله

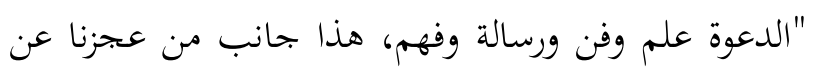

${ }^{18}$ Muhammad al-Ghazālì, al-Da wah fì al- 'Așr al-Hadìth (Egypt: Dār al-Shurūq, t.t.).

${ }^{19}$ Muhammad al-Ghazālì, Hamūm Dā`ìah., 18. 
Ali Saged \& Abdulmajid, "Reformers of al-Azhar in the Modern Era," Afkār Vol. 19 Special Issue (2017): 221-248

تبليغ دعوتنا، أما علم الدعوة نفسه، وتكوين الدعاة الأكفاء لما يناط بهم، فالكلام فيه مر المذاق". 20

\section{التجديد في مفهوم السياسة والاقتصاد:}

تناول الإمام مفاهيم حياتيه تتعلق بواقع الناس، وهمومهم، وقد ألف بحموعة من الكتب المتعلقة بمفاهيم السياسة والاقتصاد، من هذه

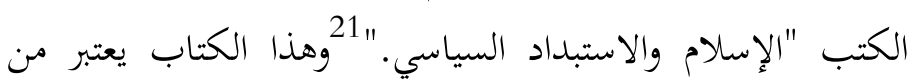
أخطر كتب الإمام حيث تميز بالجرأة والبيان، في عصر السجون والطغيان، وقد شرح الإمام واقع الحكم، ومصير الأقلام الحرة، وقول الحق، وقد نادى الإمام بعودة الشورى الإسلامية ووضع معالم السياسية الإسلامية من خلال الآتي: 1. مفهوم الحكم والسلطة والمنصب. 2. مفهوم الشورى والتخصص. 3. مفهوم العلاقة بين الحكام والمحكومين.

4. ذكر نماذج من القرون المفضلة التي اينعت ثمرتها في الفكر

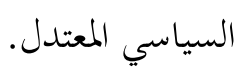

وقد شن الإمام حربا ضروسا على النظام الاشتراكي وألف كتابه المشهور (الإسلام والمناهج الاشتراكية) وقة وقد أزاح اللثام عن الإمن

${ }^{20}$ Ibid., 124.

${ }^{21}$ Muḥammad al-Ghazālì, al-Islām wa al-Istibdād al-Siyāsī (Egypt: Dār al-Nahḍah, 1997).

22 Muhạmmad al-Ghazālī, al-Islām wa al-Manāhij al-Ishtirākiyyah (Egypt: Dār al-Nahḍah, 2005). 
Ali Saged \& Abdulmajid, "Reformers of al-Azhar in the Modern Era," Afkār Vol. 19 Special Issue (2017): 221-248

خبث الاشتراكية وعيوبها، ولم يتوقف عند هذا بل كان من أكثر العلماء انتقادا للفكر العلماني والغربي، وألف في هذا كتاب (ظالام 23

(الغرب)

أحد أهم الكتب التي كتبها الشيخ محمد الغزالي للرد على المستشرقين ودعاة التغريب بأسلوب علمي رصين محكم ومعتمد على الإقناع العقلي المتماسك تحفة غزالية بالغة الإصابة للشيخ الغزالي رضي الله عنه يضيء بها الظلام الوافد من الغرب. وين الجانب الاقتصادي كان من أكثر العلماء اسفا على واقع الأمة وقد ألف كتبا في هذا ومن أشهرها (الإسلام والاوضاع الاقتصادية) ومن الجوانب التجديدية في طرح الإمام الغزالي الآتي: 1. بين الإمام أن حالة الفقر والعوز لا تتفق مع مثالية المسلم

$$
\text { التي صورها الله في كتابه. }
$$

2. ربط الإمام بين مفهوم التعبد، ومفهوم الحياة، وبين ان عمارة الحياة جزء لا يتجزأ من مفهوم العبودية لله. 3. أبرز منهجية الشريعة في تقوية المال والأعمال، ومنطلق

$$
\text { اعتماد المسلمين على انفسهم. }
$$

الفساد السياسى مرض قديم في تاريخنا هناك حكام حفروا خنادق بينهم وبين جماهير الأمة لأن أهواههم طافحة وشهواهم جامعة لا

${ }^{23}$ Muhammad al-Ghazāli, Zulām min al-Gharb (Damascus: Dār alQalam, 1999).

24 Muhammad al-Ghazāli, al-Isläm wa al-Wada'u' al-Iqtișādiyyah (Egypt: Dār al-Kutub al-Hadithah, 1963), 6. 
Ali Saged \& Abdulmajid, "Reformers of al-Azhar in the Modern Era," Afkār Vol. 19 Special Issue (2017): 221-248

يؤتمنون على دين الله ولا على دين الناس ومع ذلك فقد عاشوا آمدا

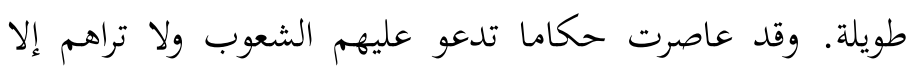
حجارة على صدرها توشك أن تشمه. انتفع بهم الاستعمار الشرقي

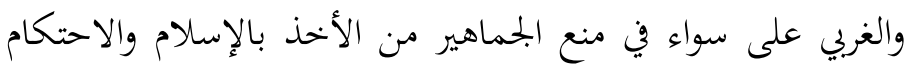

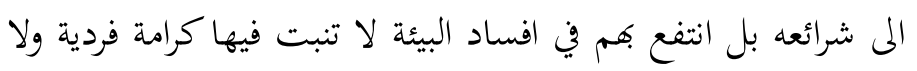
حرية اجتماعية أيا كان لوغا. 25

\section{معالم التجديد في الرد على النصارى:}

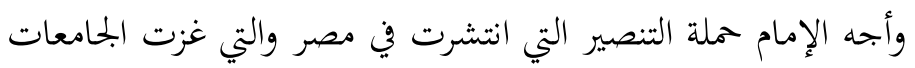
والمعاهد المصرية، وقد كانت كتابات الإمام محل اعجاب وإشادة في الداخل والخارج، وقد كان الإمام على اطلاع بواقع الدعوة، وشبه ولثابه

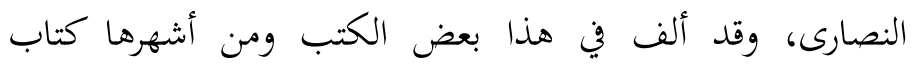
(قذائف الحق) 26 يخاطب الكتاب جيل السبعينيات، كتبه الشيخ الغزالي دفاعا عن المشروع الإسلامي و مبادئ الإسلام التي طالتها

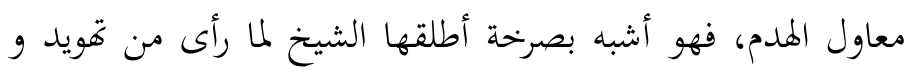
تحريف و افتراء و تصحيف وكذب تزييف طال معالم هذا الدين

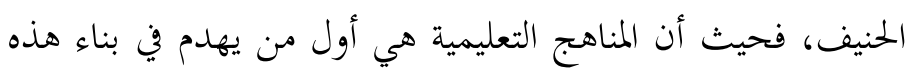

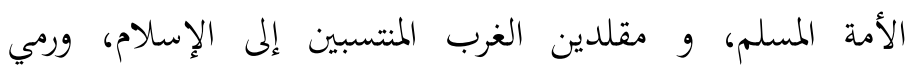

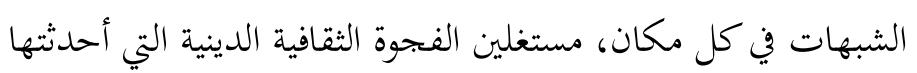

${ }^{25}$ Muhammad al-Ghazālì, Hamūm Dā ìyah., 111.

${ }^{26}$ Muḥammad al-Ghazālì, Qazā'if al-Haqq (Damascus: Dār al-Qalam, 1991). 
Ali Saged \& Abdulmajid, "Reformers of al-Azhar in the Modern Era," Afkār Vol. 19 Special Issue (2017): 221-248

مناهجهم التعليمية، فأصبحوا يشغبون على الناس و الطلبة البسطاء، حتى المثقفين طالتهم هذه الحمالات.

قال عنه أحد الكتاب "اعتلى الشيخ محمد الغزالي حصون الإسلام وقلاعه المتينة، ونصب المنجنيق، وارتمى على ثغرات الحصن، يصوّب قذائفه نحو الأعداء؛ تلفّت حوله فألفى الوحدة القاتلة، والغياب المخزي، شنق عصا المنجنيق للخلف، وألقمها قذائفه، ثمّ أرسلها تشقّ غشاوة الظلام، وترسم سنا قوس منير، بهر عيون الجموع

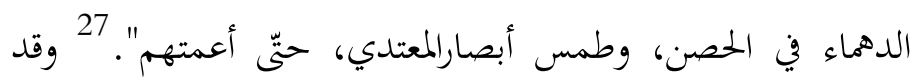
ألف الإمام كتابا آخر بعنوان "صيحة تحذير من دعاة التنصير". 28

\section{معالم التجديد في مجابهة الفكر الغربي:}

قال رحمه الله في مطلع كتابه ( كفاح الدين): "أليس عجيبا ان يظل الغرب -مع تفوقه العلمي الظاهر-صريع أحقاد قديمة وأفكار بالية، وأحكام يرسلها على الناس إرسالان لا يضبطها عقل، ولا يزها

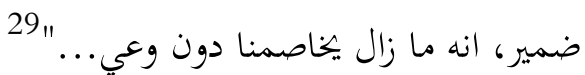
وقال رحمه في نفس الكتاب:"هل يصدق القارئ أن أحقاد أوربا على الاسلام لم تمدأ في قرن من القرون القديمة، والحديثة، وان

27 Good "Qazā'if al-Haqq", http://www.goodreads.com/book/show/6184228

${ }^{28}$ Muḥammad al-Ghazālì, Șịhah Tah̆zìr min Da ah al-Tanșīr (Egypt: Dār al-Nahḍah).

${ }^{29}$ Muhammad al-Ghazālī, Kifāh al-Dīn (Egypt: Dār al-Bayān), 5. 
Ali Saged \& Abdulmajid, "Reformers of al-Azhar in the Modern Era," Afkār Vol. 19 Special Issue (2017): 221-248

عاطفتها هذه ضد الدين النقي الطيب، فقد ترجمت عنها فيما شرعت من قوانين، لا لتعاقب بها المسلمين كأفراد، بل لتنكر

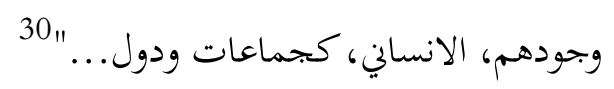
معالم التجديد عند الإمام أبو زهرة: 31 يعتبر الإمام محمد أبو زهرة من بحددي العصر الحديث، وممن أسهموا في اثراء الفكر الإسالامي بجملة من الحقائق الفكرية، ومن الذين انبروا للجهاد الفكري والعلمي وقد وقف الإمام أبو زهرة على قضايا عصرية كثيرة ومن أهم هذه القضايا التجديدية الآتي: معالم التجديد في نقض نظرية الربا: تزامن ظهور هذا الإمام مع دخول الربا مصر، وانتشاره في جل البلاد الإسلامية والعربية، ولم يقف الإمام مكتوف اليدين، لكنه فند شبه

${ }^{30}$ Ibid., 107-108.

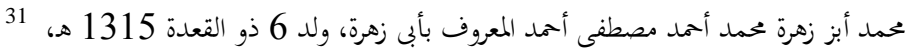

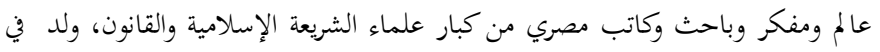

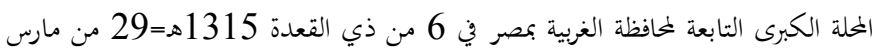

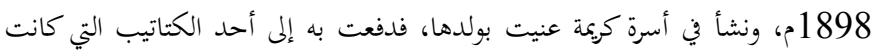

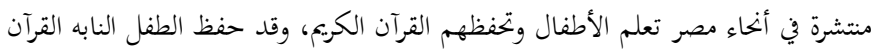

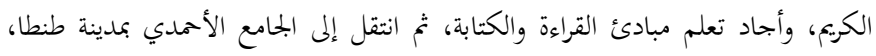

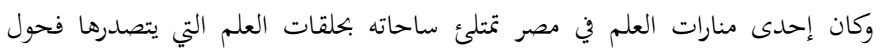

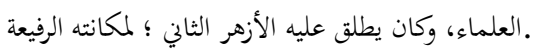

Muhammad 'Uthmān Shabīr, Fatawa al-Shaykh Muhammad Abū Zahrah (Damascus: Dār al-Qalam, 2006). 
Ali Saged \& Abdulmajid, "Reformers of al-Azhar in the Modern Era," Afkār Vol. 19 Special Issue (2017): 221-248

الربا، وبين نظرية الإسلام في التعاملات المالية وقد ألف كتابه المشهور "تحريم الربا تنظيم اقتصادي"32 ومن الجميل في طرح الإمام الآتي:

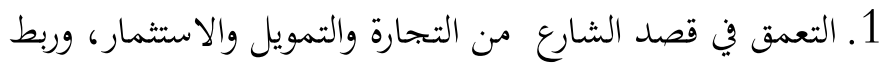
كل ذلك برؤية اقتصادية عميقة تنطلق من مبدأ رفع الضرر، وفتح باب الاستثمار، والتزاوج بين القطاعين الخاص والعام، وقواعد العرض والطلب. 2. دراسة واقع الربا وانه جاء لتعميق المشاكل، والاضرار بالسلم الاجتماعي العام، إذا أصبح المال دولة بين الأغنياء، شقي أغنياء ذلك البمتمع وفقراؤه، والربا يركز المال في أيدي فئة قليلة من أفراد البحتمع الواحد، ويحرم منه الجموع الكثيرة، وهذا خلل في توزيع المال، وهو الذي يجعل اليهود يصرون على التعامل بالربا، ونشرِه بين العباد، كما يحرصون على تعليم أبنائهم هذه تهري المهنة، كي يسيطروا على المال ويكوزوه إلى خزائنهم.

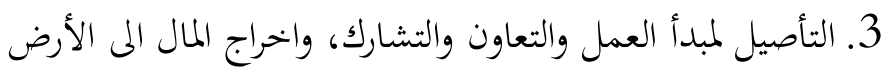
كي يتحول الى مصانع ومعامل وشركات استثمارية. التجديد في مفهوم العقوبة والتعزير:

${ }^{32}$ Muḥammad Abū Zahrah, Tahrìm al-Ribā Tanz̦ìm Iqtișādì (Saudi Arabia: Dār al-Nashr wa al-Tawzi`, 1995). 
Ali Saged \& Abdulmajid, "Reformers of al-Azhar in the Modern Era," Afkār Vol. 19 Special Issue (2017): 221-248

شن أعداء الاسلام حملة على العقوبات والجزاءات والتعزيرات في

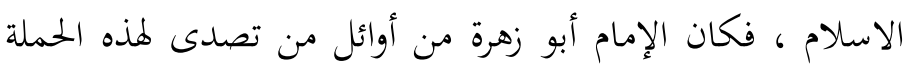

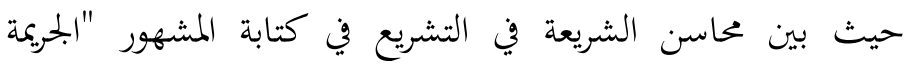

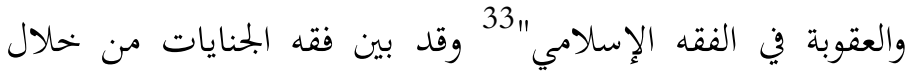

1. قصد الشارع من العقوبات هو الزجر، والمنع، وتنقية البحتمع من

$$
\text { الرذيلة، وبتسيد مبدأ الثواب والعقاب. }
$$

2. بيان عمق التشريع في معالجة الجريمة، فالقرآن الكريم يقول

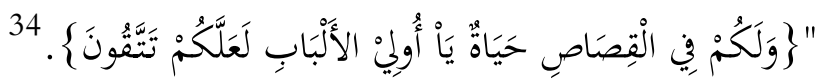

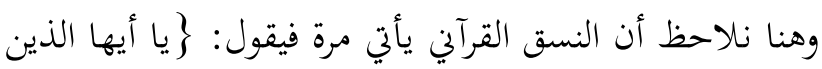

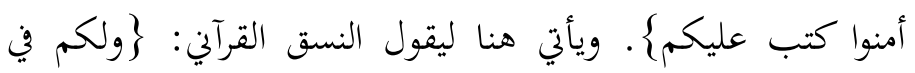

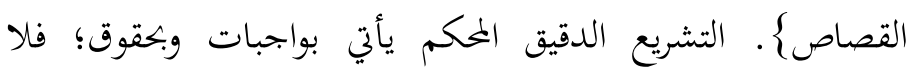

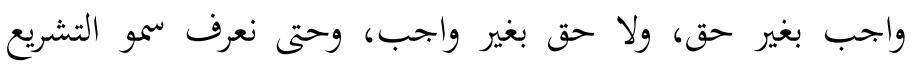

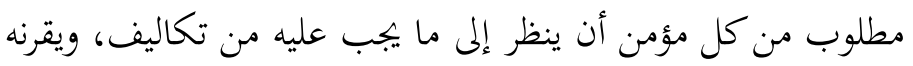

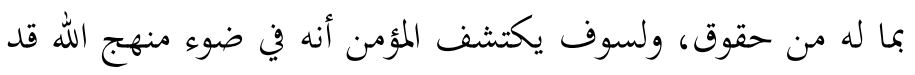

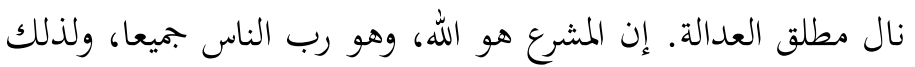
فلا يوجد واحد من المؤمنين أولى بالله من المؤمنين الآخرين. 35

${ }^{33}$ Muhammad Abū Zahrah, al-Jarìmah wa al- 'Uqūbāt fī al-Fiqh alIslāmì (Cairo: Dār Fikr al-'Arabī).

${ }^{34}$ Surah al-Baqarah 2:179.

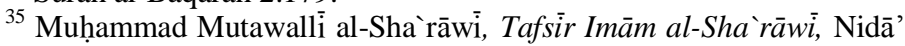
al-Īmān, http://www.al-eman.com. 
Ali Saged \& Abdulmajid, "Reformers of al-Azhar in the Modern Era," Afkār Vol. 19 Special Issue (2017): 221-248

إن التكليف الإيماني يمنع الظلم، ويعيد الحق، ويحمي ويصون

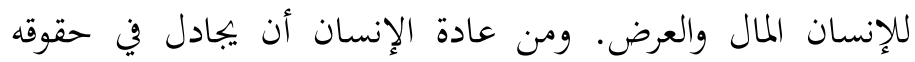

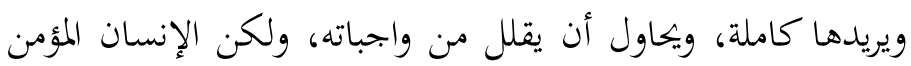

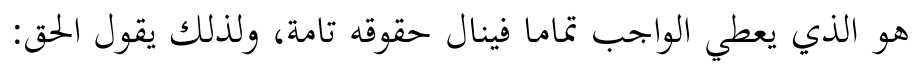

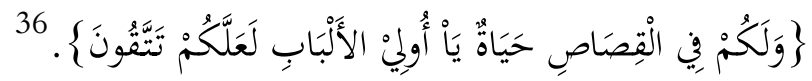

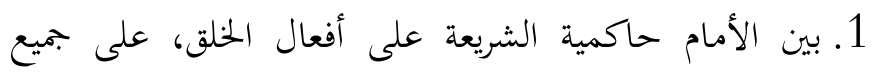
أفعال العباد، ليس فقط العبادات، بل المعاملات والجنايات، وان القصد من الجنايات الحفاظ على المجتمع من الرذيلة، قال

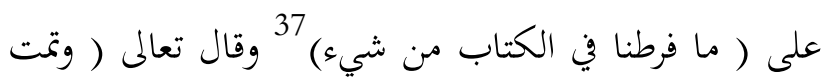
كلمة ربك صدقا وعدلا).

2. التجديد في بحال مقارنة الأديان، والرد على النصارى، وقد صداند

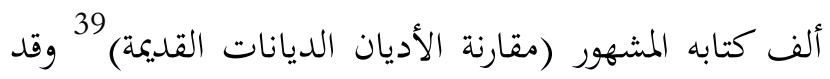
تضمن الكتاب شرحا وافيا لحالة الأديان، وبيان اتفاق الأديان في روح العقيدة والتشريع، وبيان تحريف النصارى للكتب

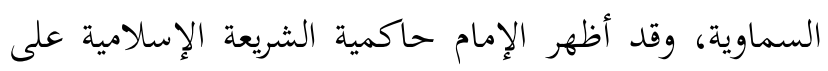
بقية الأديان، ثم ألف كتابه الآخر في بيان الديانة النصرانية

\footnotetext{
36 Surah al-Baqarah, 179.

${ }^{37}$ Surah al-An`am, 39.

${ }^{38}$ Surah Hud, 119.

39 Muhammad Abū Zahrah, Muqāranah al-Adyān al-Diyānāt alQadìmah (Cairo: Dār al-Fikr al-`Arabī).
} 
Ali Saged \& Abdulmajid, "Reformers of al-Azhar in the Modern Era," Afkār Vol. 19 Special Issue (2017): 221-248

(محاضرات في النصرانية). 40ميز طرح الإمام أبو زهرة بمعرفة ودراية بواقع الديانة النصرانية، وأظهر دراية عميقة بواقع التاريخ النصراين.

3. التجديد في العلاقات الدولية، وبيان قواعد الإسلام في التعامل بين الدول، وهذا طرح وقد أحسن حينما ألف كتابه الرائع (العلاقات الدولية في الإسلام). 41 4. وقد اشتمل الإسلام على روح الإسلام في بناء العلاقات بين الدول، وبين النظام الدولي في العلاقات بين الدول.

\section{التجديد في رده على النصارى:}

ألقى رحمه الله جملة من المحاضرات ثم جمعها في كتاب، أسماه محاضرات في النصرانية"42 حيث قال في مطلع الكتاب: "فهذه محاضراتي في النصرانية أعيد طبعها، بعد أن ألح الكثيرون في طلب الإعادة، إذ تعذر على مريدي قراءةًا الحصول عليها، حتى أهما عندما قررت دراستها على طلبة معهد الدراسات الإسلامية لم يجد الدارسون ما يراجعون فيه، فلم يكن بد من أن يعيد المعهد طبعها ليعين الدارسين، ولينتشر تلك الحقائق، من غير قجم على متدين، ولا

${ }^{40} \mathrm{Ibid}$.

${ }^{41}$ Muḥammad Abū Zahrah, al- 'Alāqāe al-Dawliyyah fì al-Islām (Cairo: Dār al-Fikr al-'Arabī, n.d).

${ }^{42}$ Muhammad Abū Zahrah, Muhạạarāāt fī al-Nașrāniyyah (Cairo: Dār al-Fikr al-`Arabī, 1966). 
Ali Saged \& Abdulmajid, "Reformers of al-Azhar in the Modern Era," Afkār Vol. 19 Special Issue (2017): 221-248

مضايقة لغير مسلم، لأن البحث الذي يتبع فيه المنهاج العلمي السليم، لا يصح أن تضيق به الصدور، ولا أن تنزوي عنه العقول.

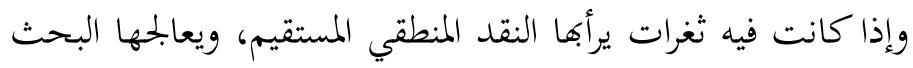

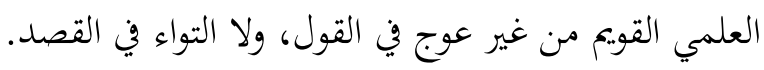

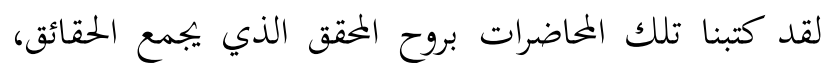
ويعرضها، وقد تماسك بعضها ببعض، ليتكون من ذلك بحموعة

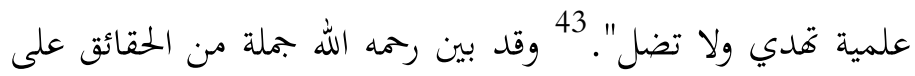

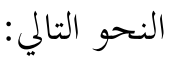

1. حالة المسيحية في عهد المسيح، وكيف تعرضت للتحريف، وكيف تأثرت بالفسلفة اليونانية، حيث قال رحمه الله :" كانت المشكلة الفلسفية التي واجهت أولاً الإغريق هي: "ما مبدأ كل شيء؟" "وباجتهاد الفلسفة في الإجابة عن هذا السؤال إجابة محدودة ومقنعة شيئاً فشيئاً كان لنا تلك المذاهب الفلسفئية التئي تتابعت في تاريخ الفلسفة الإغريقية. هذه فلسفة بدأت طبيعية

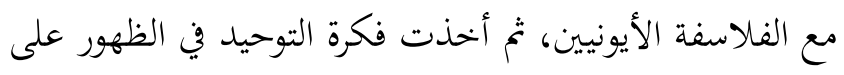
أيدي سقراط، وأفلاطون، وأرسطو، بحيث رأى هؤلاء أن المبدأ الذي صدر عنه العالم هو الله الواحد الذي لم يتغير، على لئل

${ }^{43}$ Muhạmmad Abū Zahrah, Muhạậarāt, 3. 
Ali Saged \& Abdulmajid, "Reformers of al-Azhar in the Modern Era," Afkār Vol. 19 Special Issue (2017): 221-248

غموض في تعيين هذه الصفات ونخوها مما يصح أن يتصف ب6ا"

2. مصادر التشريع في الديانة النصرانية حيث قال:"الكتاب المقدس

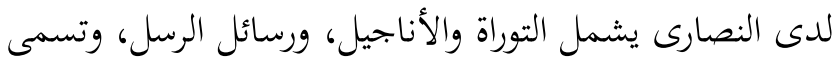

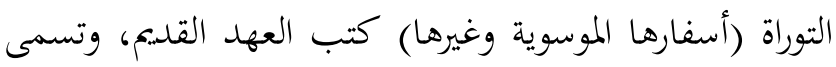
الأناجيل، ورسائل الرسل كتب العهد الجديد، فمن العهد القديم يعرفون أخبار العالم في عصوره الأولى، وأجياله القديمة، وشرائع اليهود الاجتماعية والدينية، وتاريخ نشأقم، وحكوماقم وحوادثهم، والنبوات السابقة منذ هبوط الإنسان على هذه الأرض، والبشارات بالنبيين اللاحقين، وبالمسيح، وفيها يجدون أدعية متوارثة تعين على أداء العبادات، والقيام بالطقوس الدينية

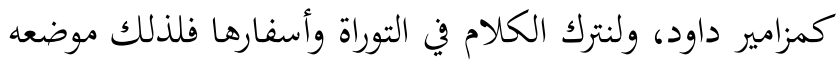
من الدراسة للديانة اليهودية، بيد أنه يجب أن يلاحظ أن بعض الأسفار المعتبرة عند اليهود مرفوضة عند المسيحيين، لعدم 45 اعتقادهم بصحة الوحي فيها.

وهذا الكلام يضم في طياته جملة من الأغلاظ العلمية والتاريخية

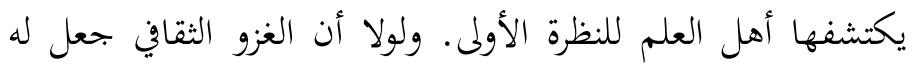

${ }^{44}$ Ibid., 37.
${ }^{45}$ Ibid., 40. 
Ali Saged \& Abdulmajid, "Reformers of al-Azhar in the Modern Era," Afkār Vol. 19 Special Issue (2017): 221-248

رواجا وسخر له أتبع ماعنينا باثباته والرد عليه. وما العمل اذا كانت

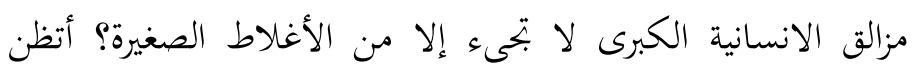

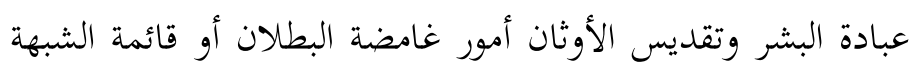
حتى يتعلق بها الألوف ويدافعون عنها بالدماء.

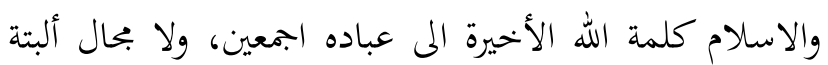
لأي إنسان كى ينقح شيئا ما في رسالته لا في كتابه ولا في سنته.

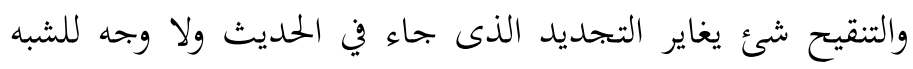

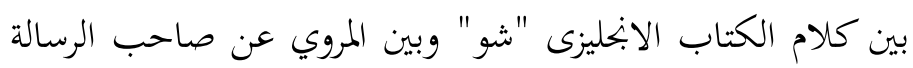

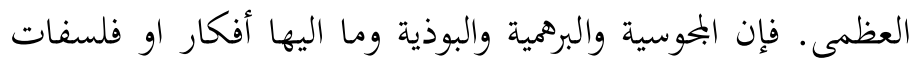

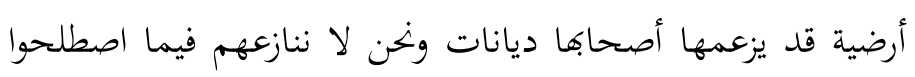
عليه. ومن هنا فكل تسوية بين صليبية اليوم وفطرة الاسلام فهي

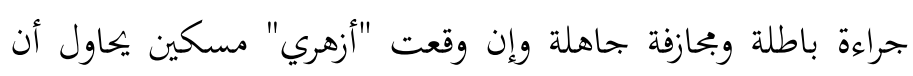
يكون "عصريا". وقد كتب عالمان من علماء الأزهر هذه الآراء فاستنكرت في

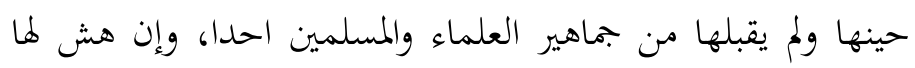

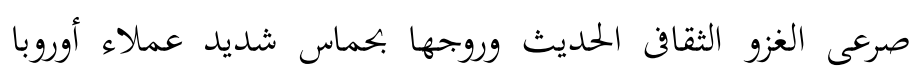
الذين يكافحون سرا وعلنا حتى لا تقوم للإسلام دولة. 46 نتائج البحث

\footnotetext{
${ }^{46}$ Muhammad Abū Zahrah, Kayf Nafham al-Islām, 161-162.
} 
Ali Saged \& Abdulmajid, "Reformers of al-Azhar in the Modern Era," Afkār Vol. 19 Special Issue (2017): 221-248

1. أكرم الله هذه الأمة بالتجديد في الدين، لأجل حفظ دينه الذي

$$
\text { تكفل بكفظه. }
$$

2. تعتبر مدرسة الأزهر وجامع الأزهر مصنع للتجديد والمحددين.

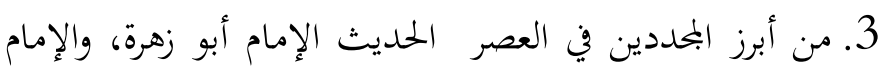

محمد الغزالي.

4. تميز بتحديد الإمامين بمناقشة قضايا العصر، والولوج في القضايا

$$
\text { المعاصرة. }
$$

5. استطاع الإمامان ان يعيا فهم الدين، وأن يكون لهما حضورا

$$
\text { علميا في جل البحالات الفكرية والعلمية. }
$$

6. نالت كتب الإمامين شهرة واسعة وكانت ينبوع صافي يهرف منه

$$
\text { العلماء، والدعاة. }
$$

7. واجه الإمامان المجمة الشرسة من قبل العلمانيين، والنصارى، الهاء.

بعلم وحلم، واستطاعا ان يفندا كل الشبه التي شيعت على لى لئل

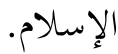

\section{References}

Abū Dāwūd, Sulaymān al-Sijistāni. Sunan Abū Dāwūd, ed. Muhammad Muhyī al-Din `Abd al-Ḥamid. Beirut: al-Maktabah al-`Așriyyah, n.d.

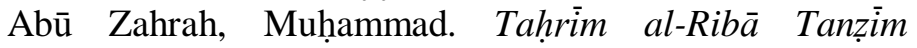
Iqtișādì. Saudi Arabia: Dār al-Nashr wa al-Tawzi’, 1995.

Abū Zahrah, Muḥammad. Al-Jarimah wa al- 'Uqūbāt fī alFiqh al-Islāmì. Cairo: Dār Fikr al-`Arabī, n.d. 
Abū Zahrah, Muhammad. Muqāranah al-Adyān alDiyānāt al-Qadìmah. Cairo: Dār al-Fikr al-'Arabī.

Abū Zahrah, Muhammad. Al-`Alāqāt al-Dawliyyah fī alIslām. Cairo: Dār al-Fikr al-`Arabī, n.d.

Abū Zahrah, Muhammad. Muḥạdarāt fī al-Naṣrāniyyah. Cairo: Dār al-Fikr al-`Arabī, 1966.

Basṭāmī, Maḥmūd Sa'ìd Khayr. Mafhūm Tajdìd al-Dīn. Jeddah: Markaz al-Ta'șīl li al-Dirasat wa al-Buhūth, n.d. Data.bnf.fr, "Muhammad al-Gazālì", accessed 10 Oct 2015, http://data.bnf.fr/ark:/12148/cb12067665m

Al-Fārābī, Abū Nașr Ismā'ìl al-Jawharì. Al-Ṣiḥah. Beirut: Dār al-`Ilm li al-Malāyīn, 1987.

Al-Ghazāli, Muhammad. Sir Ta'akhkhar al-`Arab alMuslimin. Egypt: Țab`ah Dār al-Nahḍah.

Al-Ghazālì, Muhammad. Al-Islām wa al-Ṭāqāt alMu'ațtalah. Egypt: Dār al-Nahḍah, 2005.

Al-Ghazāli, Muḥammad. Jaddid Hayātak. Egypt: Dār alDa`wah li al-Nashr wa al-Tawzi’, 1989.

Al-Ghazālì, Muhammad. Kayf Nafham al-Islām. Egypt: Dār al-Da`wah, t.t.

Al-Ghazālì, Muḥammad. Hamūm Dā'iyah. Egypt: Dār alNahḍah, 1996.

Al-Ghazālì, Muḥammad. Al-Da`wah fī al-'Așr al-Hadìth, Egypt: Dār al-Shurūq, t.t.

Al-Ghazālì, Muhammad. Al-Islām wa al-Istibdād alSiyāsì. Egypt: Dār al-Nahḍah, 1997.

Al-Ghazālì, Muhammad. Al-Islām wa al-Manāhij alIshtirākiyyah. Egypt: Dār al-Nahḍah, 2005.

Al-Ghazālì, Muhammad. Zulām min al-Gharb. Damascus: Dār al-Qalam, 1999.

Al-Ghazālì, Muhammad. Al-Islām wa al-Waḍ'u' alIqtiṣādiyyah. Egypt: Dār al-Kutub al-Hadìthah, 1963.

Al-Ghazāli, Muhammad. Qazā'if al-Haqq. Damascuc: Dār al-Qalam, 1991.

Al-Ghazāli, Muhammad. Șihah Taḩzir min Da`ah alTanșìr. Egypt: Dār al-Nahụah. 
Ali Saged \& Abdulmajid, "Reformers of al-Azhar in the Modern Era," Afkār Vol. 19 Special Issue (2017): 221-248

Good Reads, “Qazā'if al-Haqq", http://www.goodreads.com/book/show/6184228 Ibn `Asākir, Tabi `in Kazib al-Muftar. t.pt: tp., t.t.

Ibn Manz̄ūr al-Anșārí, Muhammad bin Mukarram Jamāl al-Dīn. Lisān al-'Arab. Beirut: Dār Șadir, 1414H.

'Imārah, Muḥammad. Al-Shaykh al-Ghazālì al-Wāqi alFikr wa al-Ma'ārak al-Fikriyyah. Egypt: Dār al-Rashād li al-Nashr wa al-Tawzi', 1997.

Al-Qarāḍāwī, Yūsuf. Al-Imām al-Ghazālì mā 'Araftah. Egypt: Dār al-Shurūq, 2008.

Shabīr, Muhammad 'Uthmān. Fatawa al-Shaykh Muhammad Abū Zahrah. Damascus: Dār al-Qalam, 2006.

Al-Sha `rāwi, Muhammad Mutawallī. Tafsìr Imām alSha 'rāwì, Nidā' al-Īmān, http://www.al-eman.com.

'Umar Sāmì, al-Ahrām, published 21 Oct 2013. 